Mundo Agrario vol. 18, no 38, e061, agosto 2017. ISSN 1515-5994

Universidad Nacional de La Plata.

Facultad de Humanidades y Ciencias de la Educación.

Centro de Historia Argentina y Americana

\title{
Estudo descritivo do perfil sociodemográfico da população urbana e rural no estado de Minas Gerais
}

\section{Descriptive study of sociodemographic profile of population urban and rural at state of Minas Gerais}

\author{
Nayhara Freitas Martins Gomes *, Ana Louise de Carvalho Fiúza **, \\ Marco Aurélio Marques Ferreira **, Neide Maria de Almeida Pinto ***
}

* Instituto de Geociências da Universidade Federal de Minas Gerais (IGC/UFMG), Brasil, ** Departamento de Economia Rural da Universidade Federal de Viçosa (UFV), Brasil, *** Departamento de Economia Doméstica da Universidade Federal de Viçosa (UFV), Brasil | nayhara martins@yahoo.com.br; louisefiuza@ufv.br; marcoaurelio@ufv.br; nalmeida@ufv.br

\section{PALAVRAS CHAVE RESUMO}

Campo Este artigo teve por objetivo compreender como as variáveis relacionadas ao tipo de trabalho, à renda, ao acesso a bens de consumo, a serviços e tecnologias da informação e da comunicação manifestam-se no perfil das famílias

Cidade que habitam o campo no Brasil. Utilizou-se dados da Pesquisa Nacional de Amostra de Domicílios (PNAD), referentes ao estado de Minas Gerais. Observou-se, em termos dos resultados finais, que o processo de mudança do

Modos de vida rural e urbano modo de vida rural se dá de forma mais visível nas variáveis relacionadas ao consumo, no que se refere ao acesso à

Perfil sociodemográfico bens e serviços de origem urbana.

Brasil

\section{KEYWORDS ABSTRACT}

Field This article aimed to understand how variables related to the type of work, income, access to goods, services and information and communication technologies are the profile of families inhabiting the field in Brazil. We used data

City from the National Household Sample Survey (PNAD), refering to the State of Minas Gerais. It was observed, in terms of final results, that the process of change of the rural way of life is most visible in the consumption-related

Urban and rural ways of life variables, as regards access to goods and services of urban origin.

Socio-demographic profile

Brazil 


\section{Introdução}

O objetivo deste artigo é analisar as transformações no modo de vida dos moradores de comunidades rurais em um pequeno município de economia cafeeira situado na Zona da Mata mineira que como tantos outros, a partir dos anos de 1990, passam a exibir de forma mais evidente os reflexos do fenômeno da industrialização, bem como manifestações advindas da diversificação do mercado de trabalho e de produtos. No caso do Brasil, estas transformações econômicas passam a ser complementadas, ainda, pelo crescimento de uma renda não-agrícola, advinda também da universalização do direito à aposentadoria no campo. Buscamos verificar, especificamente, como as variáveis referentes ao trabalho, à renda, ao perfil familiar, ao acesso a bens de consumo e serviços e às tecnologias da informação e comunicação são apropriadas pelos rurais, de modo a observar as mudanças no seu modo de vida. O enquadramento teórico apresentado neste artigo se constrói com base na concepção de que o campo vem se tornando um espaço híbrido (Burke, 2003 e Canclini, 1998) em função do processo de urbanização ${ }^{1}$. Estudiosos como Biazzo (2008), Sánchez (2009), Sobarzo (2010) procuram estabelecer distinções quanto aos conceitos de campo e rural, assim como de cidade e urbano empreendendo estudos no sentido de definir o rural e o urbano como qualidades das relações sociais. De acordo com esta perspectiva, o rural e o urbano podem conviver no mesmo local através das práticas construídas pelos sujeitos. Nos trabalhos de Lefebvre (2008) e Milton Santos (1993, 2003), os conceitos de cidade e de campo são vistos como espaço, enquanto urbano e rural se referem ao conteúdo social das formas espaciais. Já nos estudos de Wanderley (2009) e de Carneiro (2012), campo, rural e ruralidade são correspondentes, evidenciando-se a dimensão simbólica e as representações sociais expressas pelos sujeitos. Na visão das autoras Kageyama (2008), Wanderley (2009) e Carneiro (2012), as relações no campo são marcadas pela nova ruralidade que é concebida como comportando práticas antigas ressignificadas.

Wanderley (2009) não nega que a sociedade rural vem se transformando em decorrência da influência da cultura urbana. Contudo, a autora se opõe à ideia de que o urbano poderia exercer efetivo domínio sobre o rural em que o desfecho seria o fim do rural com a sua plena urbanização. Pelo contrário, para Wanderley (2009), tanto o rural quanto o urbano em suas novas e atuais formas permaneceriam adequados para analisar as relações sociais e espaciais da sociedade moderna apontando assim, não para o fim do rural, mas para a emergência de uma nova ruralidade.

Diante desta discussão, o presente artigo pretende contribuir com reflexões acerca das transformações que vem sendo experimentadas pelas sociedades rurais resultantes das trocas estabelecidas com o modo de vida urbano. Adota-se a perspectiva teórica que interpreta os modos de vida rural e urbano, e os aspectos socioculturais que esta lhes confere, como não sendo restringidos a limites espaciais determinados. Nesta seara observa-se um processo de hibridismo cultural entre os modos de vida rural e urbano. Para tais autores haveria uma tendência global de hibridização frente aos processos de globalização que levariam a uma complexa relação de convivência entre a tradição e a modernidade.

Segundo Teixeira e Lages (1997) torna-se cada vez mais difícil encontrar modos de vida específicos do campo ou da cidade, ainda que não se possam desconhecer as especificidades históricas que caracterizam de forma singular cada assentamento humano. Contudo, superou-se a perspectiva dicotômica que caracterizava o campo e a cidade como espaços com características antagônicas. A mobilidade espacial, a acessibilidade a bens e serviços, à informação e à infraestrutura dissolveram as diferenças entre os modos de vida no campo e na cidade.

Entretanto, a aproximação entre esses espaços, de acordo com Wanderley (2009), e Camargo e Oliveira (2012), não se traduz na afirmação do fim do rural. A perspectiva dessas autoras é que o campo está em íntima relação com a cultura urbana, com a qual partilha semelhanças e descontinuidades, mas cujo processo de inter-relação não destrói as suas particularidades. Autores como Silva (1997), Veiga (2002), dentre outros, evidenciaram que o campo não era sinônimo de agrícola, ao mostrar as ocupações não agrícolas que nele se desenvolviam, combinadas com atividades agrícolas. Neste sentido, é necessário fazer menção ao conceito de pluriatividade que associa-se à combinação de atividade agrícola e não agrícola, já as atividades não agrícolas referir-se-iam àquelas atividades não relacionadas diretamente com as atividades agrícolas, mas que ainda assim poderiam ser exercidas 
no campo (Carneiro, 1998). Assim, a pluriatividade implicaria na existência de atividades não agrícolas, mas as atividades não agrícolas não implicariam na presença de pluriatividade (Souza e Souza, 2008).

Santos (2003), Kageyama (2008) assumem uma abordagem territorial colocando que a relação entre o campo e a cidade poderia se dar em territórios predominantemente rurais, ou em territórios predominantemente urbanos ou, ainda, em territórios relativamente urbanos. Silva (1997), a partir do Projeto Rurbano $\stackrel{2}{ }$, trouxe o conceito novo rural, apontando para o contexto cada vez mais intenso de urbanização do campo através do acesso às tecnologias, às informações, aos bens de consumo e ao processo de modernização da agricultura.

Segundo Favareto (2007), a intensificação das relações entre o campo e a cidade se manifesta por meio da unificação dos mercados de trabalho e de consumo, bem como através da criação de instituições formais que regulam as formas de uso desses espaços. Segundo o autor, a ruralidade contemporânea é marcada pela diversificação produtiva e uma heterogeneidade social crescente. As atividades primárias ligadas à agricultura e à pecuária cedem espaço a uma maior diversificação com crescente diferenciação social. Segundo Endlich (2010), o urbano é caracterizado como modo de vida que se estende para além dos espaços físicos da cidade e contribui para as transformações das atividades desenvolvidas no campo. A autora afirma que o Brasil é mais urbano do que se imagina, pois ao considerar os modos de vida dos indivíduos que vivem no campo e em pequenas cidades observa-se uma forte influência urbana.

Já Veiga (2002) procurou demonstrar que o Brasil é menos urbano do que se calcula, ao observar uma parcela do país considerada urbana, mas cujas dinâmicas econômica, social, política e cultural são inequivocamente rurais. Para tal autor é preciso compreender que o rural não pode ser identificado apenas com aquilo que está fora do perímetro urbano dos municípios brasileiros, muito menos com as atividades exclusivamente agropecuárias. Assim, o autor lança luz para o fato de que o rural é necessariamente territorial e não setorial.

Para Rambaud (1969), autor francês contemporâneo de Lefebvre, o campo e a cidade estão envolvidos em uma dinâmica universal dada pelo processo de urbanização dos modos de vida. Segundo este autor, as formas urbanas de se viver nasceram na cidade, mas ultrapassaram os seus limites e passaram a ser reproduzidas no campo. Cada indivíduo "escolheria" a partir dos seus interesses o que o autor denomina de canivar, entendido como uma escolha de elementos da cultura urbana para compor seu modo de vida. O canivar se constituiria em uma expressão do ideário de projeto de vida que o sujeito do campo possui. Para o autor, os rurais "incorporariam" modos de vida urbanos em suas relações, através da aquisição de bens de consumo e de serviço que chegam ao campo.

Com base no aporte teórico elaborado, as categorias analíticas campo ruralizado e campo urbanizado são utilizadas neste texto por realçarem o nível de transformações observadas nos modos de vida dos rurais, nomeadamente, aquelas relativas às mudanças em termos do trabalho, da escolarização, da renda, do acesso a bens de consumo e aos serviços urbanos, bem como às tecnologias da informação e da comunicação. A variável trabalho está sendo analisada -neste artigo- considerando-se a presença de atividades não agrícolas exercidas por algum dos membros da família que vive em uma propriedade rural. É importante considerar que a realização de uma ocupação não agrícola por parte de algum dos membros da família pode inclusive repercutir em uma possibilidade de retroalimentação das atividades agrícolas, como mostrou Nascimento (2014) ao estudar o turismo rural na região serrana do Espírito Santo. Nesta região capixaba o agroturismo é o exemplo mais contundente de que a atividade não agrícola pode manter associada à unidade de produção e de consumo, ainda que este último não se constitua mais em um consumo para a autossustentação.

O próprio tempo dedicado ao trabalho em um campo com fortes traços de ruralidade operaria, segundo Bagú (2005), está de acordo com o tempo natural, enquanto em um campo urbanizado o uso da técnica imprimiria ao trabalho a precisão do tempo horário, típico da cidade. Nesse sentido, a transição de uma sociedade tradicional para uma sociedade capitalista introduziria mudanças nas noções de tempo e de trabalho, modificando sobremaneira os modos de vida no campo. 
Outro indicador dos processos de mudança no campo, para Favareto (2007), seria a renda. Ela introduz no campo uma reviravolta, símbolo de segurança de ganho. No rural tradicional a autossubsistência tornava dispensável a racionalidade econômica com base no cálculo. A exploração agrícola não tinha como objetivo direto o lucro, ela se reproduzia dentro de uma lógica pré-capitalista. Quanto ao acesso ao ensino, em sociedades rurais em transformação este passa a ser visto, segundo Wanderley (2009), como um fator e uma condição para o crescimento do bem estar da família. A sociedade rural deseja cada vez mais um ensino além do primário, voltado para apreensão de uma profissão além daquela de agricultor. Assim, o acesso ao ensino secundário e técnico insere o rural em um processo complexo de mobilidade profissional, cultural e espacial. Mas ainda assim, os habitantes do campo permanecem com maiores chances que os urbanos de entrarem mais cedo no trabalho, como apontam os dados do IBGE (2011). Outros indicadores do processo de urbanização considerados neste estudo são: o acesso dos habitantes do campo a bens de consumo e a serviços urbanos, bem como o acesso às tecnologias de comunicação e informação.

\section{Material e Métodos}

Utilizou-se neste artigo uma análise exploratória dos dados, aplicando-se o teste t para amostras independentes, bem como os testes de qui-quadrado e de correlação de Pearson. A análise foi feita utilizando-se dados referentes às unidades domiciliares da Pesquisa Nacional de Amostra por Domicílios (PNAD) de Minas Gerais, de 2011, relativas ao perfil socioeconômico, às características do trabalho, ao acesso à informação e aos bens de consumo e aos serviços públicos. A escolha do estado de Minas Gerais justifica-se pela carência de estudos vinculados ao debate sobre os processos de mudanças oriundos da aproximação entre o campo e a cidade utilizando-se os dados domiciliares da PNAD. Os dados foram tratados considerando-os enquanto uma base complexa, adotando-se a retirada de valores únicos. Posteriormente, foram transpostos para o software SPSS 20.0, onde se realizou a descrição das variáveis de acordo com dicionários fornecidos pela PNAD. Por fim, realizou-se a retirada de valores considerados como extremamente discrepantes e de casos que possuíam informações incompletas.

Para a realização da análise partiu-se de uma análise exploratória dos dados (AED), posteriormente foram realizados testes $\mathrm{t}$ de médias independentes para as variáveis métricas, teste qui-quadrado para as variáveis nominais, e correlação de Pearson para duas variáveis métricas. Segundo Hair et al (2009), o teste t avalia se as diferenças entre as médias observadas ocorrem por acaso ou se houve uma diferença significativa estatisticamente. Testa-se uma hipótese nula (H0, que estabelece que as médias para as variáveis associadas serão iguais), consequentemente testa-se uma hipótese alternativa (H1). Neste estudo, adotou-se, como nível de significância o valor de $\mathrm{p}=0,05$, se o p-valor for menor que esse "ponto de corte", a hipótese nula é rejeitada. Já o teste quiquadrado é usado para testar a significância estatística entre distribuições de frequência de dois ou mais grupos de variáveis categóricas. Utiliza-se a tabulação cruzada para descrever as respostas para cada grupo e as compara, permitindo assim testar se há diferenças entre os grupos e suas relações (Hair et al, 2009).

A AED foi realizada tendo como critério a divisão da população por situação censitária: rural (0) e urbana (1). As variáveis categóricas (nominais) foram descritas em função da frequência, enquanto as métricas foram submetidas às análises de média, mediana, desvio-padrão, variância, valor mínimo e máximo, curtose e assimetria. O último procedimento de análise de dados utilizado foi a correlação de Pearson, técnica que procura avaliar se existe uma relação coerente e sistemática entre as variáveis de um estudo. A correlação de Pearson mensura a associação linear entre duas variáveis métricas (Hair et al, 2009). Para conhecer como o processo de transformação do modo de vida rural vem se constituindo no campo, tornou-se necessário estabelecer parâmetros e variáveis que ajudem a explicar o fenômeno. Contudo, ressalta-se que este artigo não pretende estabelecer padrões cristalizados sobre os modos de vida.

Autores como Waldorf (2007), Teljeur \& Kelly (2008), Puia (2011), dentre outros, apontam que em um campo em processo de urbanização observam-se diferenças em algumas características socioeconômicas quando se compara as mesmas com as que estão presentes em um campo ruralizado. Em relação ao "casamento", por exemplo, 
autores como Bourdieu (2002), apontam que o tipo de união (Tipo_uniao) estabelecido pelos indivíduos em um campo ruralizado se caracteriza pela predominância de uniões conjugais oficializadas, realizadas através do casamento no religioso e civil. Quanto às características socioeconômicas da família, no que se refere à idade a literatura aponta que há uma tendência de predominância de pessoas mais velhas e do sexo masculino em um campo mais ruralizado (Bourdieu, 2002).

No que diz respeito ao número de componentes da família (Num_comp_dom), em um campo ruralizado com predominância de atividades agrícolas, marcado por relações tradicionais, o homem tende a ser considerado como o chefe de família. As famílias tendem a ter mais de três filhos devido à importância do tamanho da família para a reprodução da unidade produtiva. Já o rendimento mensal domiciliar per capita (Rend_percapita) em um campo ruralizado está vinculado às atividades agrícolas ou aos benefícios sociais do governo. O dinheiro e a renda ainda não se mostram tão presentes nas relações de trabalho como em um campo urbanizado. Além disto, a unidade produtiva produz o essencial para o autoconsumo, não sendo tão necessária a presença do dinheiro para a realização das trocas.

Em termos dos conhecimentos formais, aqueles relativos a saber ler e escrever (ler_escrever) e ao número de anos de estudo (Anos_estudo), a literatura aponta, desde os estudos de Rambaud em 1969 até os trabalhos de Remoaldo (2002), Olatunde et al (2007), Pereira et al (2009), Puia (2011), dentre muitos outros, que no geral, em um campo ruralizado, os rurais demonstram não se voltarem para a busca de uma formação profissional, apresentando, portanto, menos anos de estudo.

No que diz respeito às transformações relacionadas ao trabalho, considerou-se que em um campo em processo de urbanização seria expressivo a existência de ORNAS (Ocupações Rurais Não Agrícolas), destacadas por Silva e Grossi (1998), Favareto e Schröder (2007), Camargo e Oliveira (2012), dentre outros. Por outro lado, em um campo ruralizado há uma tendência maior do que no campo urbanizado do indivíduo começar a trabalhar mais cedo, uma vez que em um campo ruralizado, segundo Rambaud (1973), os rurais atribuem demasiada importância ao adjetivo de trabalhador. O Quadro 1 apresenta uma síntese das variáveis utilizadas para analisar as características do trabalho, a fim de perceber se as mesmas apontam para a configuração de um campo mais ruralizado ou mais urbanizado.

\section{Quadro 1: Variáveis relacionadas ao trabalho}

\begin{tabular}{|l|c|}
\hline \multicolumn{1}{|c|}{ Descrição da variável } & Sigla \\
\hline Principal atividade desenvolvida & (Ativ_princ) \\
\hline Número de horas habitualmente trabalhadas na atividade principal & (Horastrabprin) \\
\hline Idade em que o respondente começou a trabalhar & (Idade_trab) \\
\hline $\begin{array}{l}\text { Grupamentos da atividade principal do empreendimento na semana de } \\
\text { referência }\end{array}$ & (Ramos_ativ) \\
\hline Número de trabalhos exercidos pelos respondentes & (Num_trab) \\
\hline
\end{tabular}

Fonte: Elaborado pelos autores (2014)

Diante das variáveis referentes ao acesso às tecnologias de informação e comunicação, um campo ruralizado apresenta-se pouco permeável a este tipo de tecnologia da comunicação, estando mais fechado sobre si mesmo. Já em um campo urbanizado, observa-se de modo expressivo maior busca pelo acesso e troca de informações através da internet, posse de celular e televisão. Em termos das tecnologias da informação e comunicação se considerou: o acesso à internet no domicílio (Internet_dom); a posse de telefone móvel celular (Celular), e a posse de televisão a cores (TV).

Por fim, analisaram-se neste artigo as variáveis referentes ao acesso a bens de consumo e a serviços públicos, em virtude de autores como Bibby e Shepherd (2004), Bernardelli (2010), Diniz (2013) e Nascimento et al (2013), 
dentre outros, apontarem que o processo de urbanização no campo instaura um modelo de consumo urbano voltado para a compra de bens materiais e o acesso a confortos urbanos. Assim, analisaram-se as seguintes variáveis: posse de veículo automotor (Carro_moto), posse de geladeira (Geladeira), posse de máquina de lavar (Maq_roupa), posse de fogão com mais de duas bocas (Fogao), material predominante na construção (Mat_parede), posse de água canalizada (Agua_canal), posse de iluminação elétrica no domicílio (Ilumin_dom).

\section{Resultados e discussões}

O presente estudo foi composto por uma amostra de 31.837 observações correspondentes às unidades domiciliares do estado de Minas Gerais. Sendo 27.601 casos (86,7\%) referentes à população citadina, e 4.236 casos (13,3\%) referentes à população que vivia no campo. Quanto ao sexo dos respondentes encontrou-se, no campo, 52\% de homens e $48 \%$ de mulheres, já na cidade esses dados se apresentaram de forma inversa: $48 \%$ eram homens, enquanto 52\% eram mulheres. Este dado aponta para o processo de masculinização do campo. Para Camarano e Abramovay (1998), a masculinização do campo vem acontecendo principalmente pela migração de jovens de ambos os sexos, mas principalmente das mulheres jovens e adultas para as cidades e grandes centros em busca de trabalho. Corroborando com os autores, Bourdieu (2002) discorre sobre essa realidade no campo francês, a migração feminina fica cada vez mais acentuada, em busca de trabalho e oportunidades educacionais e permanece no campo um contingente maior de homens.

Por meio do teste $T$, todas as variáveis métricas testadas apresentaram um nível de significância igual a zero $(\mathrm{p}=0,000)$, o que permitiu rejeitar todas as hipóteses nulas formuladas, baseadas na afirmativa de que as médias entre as variáveis selecionadas eram iguais. Concluiu-se que o p valor (as significâncias) eram igual a 0,00, assumindo-se que os parâmetros estimados não eram nulos. Logo, as diferenças entre as médias das variáveis selecionadas eram significativas.

No teste T para amostras independentes a variável idade obteve uma média de 34,47 anos, e a população citadina de 33,53 anos. Ao assumir que as variâncias não são iguais $(\mathrm{p}=0,00)$ percebe-se que as médias das idades entre a população urbana e a rural são diferentes. Portanto, rejeita-se H0 ( $\mathrm{p}=0,000$ que é menor que 0,05 ), ou seja, a média de idade da população que vive no campo é estatisticamente maior do que a da população citadina. Estes dados revelaram que existia uma predominância de pessoas mais velhas no campo em Minas Gerais.

No que diz respeito à média de membros por família, no campo esta foi de 4,01, sendo que o número mínimo de membros foi de 1 e máximo de 11 componentes por família. Já na cidade, o número médio de componentes foi 3,84, apresentando entre 1 a 13 membros. Assumindo-se que as variâncias não são iguais, percebe-se que as médias do número de componentes das famílias do campo e as citadinas são diferentes. Portanto, rejeita-se H0 ( $\mathrm{p}=0,00$ que é menor que 0,05$)$. Assim, o número médio de componentes das famílias que viviam no campo $(4,01)$ é estatisticamente maior do que a população citadina $(3,84)$. Como já foi apontado pela teoria, o campo em Minas Gerais apresenta uma tendência de um número maior de componentes por família do que a cidade, muito devido à maior dependência do trabalho familiar em função da unidade produtiva.

Em relação ao "tipo de união conjugal” dos respondentes observou-se que no campo o percentual de casamentos no civil e no religioso foi maior do que na cidade: $67,4 \%$ contra $56,6 \%$, confirmando a importância que os rurais atribuem à formalização dos vínculos matrimoniais. Já as relações do tipo consensuais ou informais referentes a quando uma pessoa vive em companhia do cônjuge sem ter contraído casamento civil ou religioso apresentaram maior porcentual na cidade do que no campo: $26,5 \%$ e $19,2 \%$ respectivamente. De acordo com o alfa obtido no teste de qui-quadrado (alfa $=0,05$ ) pode-se rejeitar $\mathrm{H} 0$, visto que 0,00 é menor do que 0,05 . Logo, assume-se que existe dependência entre a natureza do tipo da união e o fato de viver no campo ou na cidade. Tal constatação já aparecia em estudos como os de Bourdieu (2002) e de Silva (2013).

Quanto aos anos de estudo, a média foi de 5,12 anos no campo, enquanto na cidade foi de 7,72 anos. Assumindose que as variâncias não são iguais $(\mathrm{p}=0,00)$, percebe-se que as médias dos anos de estudo entre a população 
citadina e a que vive no campo são diferentes. Portanto, rejeita-se H0 ( $\mathrm{p}=0,00$ que é menor que 0,05). Assim, a média de anos de estudo da população rural é estatisticamente menor do que a da população urbana.

A escolaridade da população rural é um dos quesitos importantes na mensuração do processo de transformação da sociedade rural. De acordo com Rambaud (1973), a população que vive no campo, ou pelo menos parte dela, está ciente da importância do estudo na sociedade contemporânea. No entanto, segundo o mesmo autor, além das falhas do poder público na oferta de oportunidades de estudo para os rurais existiriam também fatores culturais que contribuiriam para o menor nível de escolaridade dos moradores do campo quando comparados com os citadinos, tais como: a falta de "paciência” dos mesmos para esperar o tempo necessário para o término de uma formação superior, bem como a grande importância que a sociedade rural atribuía ao trabalho fazendo com que os indivíduos começassem a trabalhar muito cedo.

Em termos de alfabetização, esta foi maior na cidade do que no campo: 87,4\% e 78,3\%, respectivamente. No que diz respeito a variável saber ler e escrever o teste de qui-quadrado mostrou-se significativo, visto que alfa foi igual a 0,00, sendo portanto menor que 0,05, o que levou a rejeitar H0. Logo, assumiu-se que existia dependência entre saber ler e escrever e o fato da pessoa viver no campo ou na cidade. Estes resultados relativos aos anos de estudos de citadinos e rurais coincidem com o apontado por pesquisas realizadas por autores tais como Rambaud (1969), Weinert \& Boik (1995), Sen (2000), Waldorf \& County (2007), United Nations (2012), dentre outros. Utilizou-se, ainda, a correlação de Pearson entre as variáveis anos de estudo e rendimento mensal per capita. Esta técnica procura avaliar se existe uma relação coerente e sistemática (associação linear) entre duas variáveis métricas (Hair et al, 2009).

Tabela 1: Resultado do teste estatístico de Correlação de Pearson

\begin{tabular}{|l|c|c|}
\hline Correlação de Pearson & Anos de estudo & $\begin{array}{c}\text { Rendimento mensal } \\
\text { per capita }\end{array}$ \\
\hline Anos de estudo & 1 & $0,330^{* *}$ \\
\hline Sigma (2 extremidades) & & 0,000 \\
\hline Rendimento mensal per capita & $0,330^{* *}$ & 1 \\
\hline Sigma (2 extremidades) & 0,000 & \\
\hline
\end{tabular}

** A correlação é significativa no nível 0,01 (2 extremidades).

Fonte: Dados do IBGE, 2011.

Os resultados do teste de correlação de Pearson descrito na Tabela 1 permitiram a rejeição da hipótese nula (H0 = não existe correlação entre nível de escolaridade e renda). Ou seja, confirmou-se que existe correlação entre o nível de escolaridade e o rendimento. Considerando ainda que a correlação de associação foi positiva, a tendência é que quanto maior a escolaridade, maior o rendimento e vice-versa. Entretanto, esta relação entre renda e escolaridade mostrou-se fraca, dado que o coeficiente de correlação $(0,330)$ mostrou-se próximo de 0 . Quando se elevou o coeficiente de correlação ao quadrado obteve-se o coeficiente de determinação R2 = 0,108. Este coeficiente é uma medida que varia entre 0 e 1, indicando, em percentagem, o quanto o modelo consegue explicar os valores observados. Isto significa que $10,8 \%$ da variação de nível de escolaridade está associada ou consegue ser explicada pela a renda, ou seja, existe correlação positiva entre estas variáveis, mas ela mostrou-se como fraca.

Aprofundando-nos mais na questão relativa ao rendimento mensal domiciliar per capita, observou-se uma média de R \$ 432,61 para a população que vivia no campo. Já a população citadina apresentou uma média superior à do campo, correspondendo a R \$ 852,63. Assumindo-se que as variâncias não são iguais, percebe-se que as médias de rendimento per capita das pessoas que vivem no campo e na cidade são diferentes. Portanto, rejeita-se H0 ( $\mathrm{p}=0,000$ que é menor que 0,05). Assim, o valor médio do rendimento per capita na cidade (R\$ 852,63) é estatisticamente maior do que aquele alcançado no campo em Minas Gerais (R\$432,61). Estes dados confirmam 
o apontado nos estudos de Graziano da Silva (1998, 2000), Favareto \& Schroder (2007), Kageyama (2008), Camargo e Oliveira (2012), dentre outros.

No que diz respeito à idade com a qual o indivíduo começou a trabalhar, no campo este fato ocorre, em média, com 11,79 anos, enquanto na cidade esta idade subiu para 15,12 anos. Assumindo-se que as variâncias não são iguais, percebe-se que as médias das idades no campo e na cidade são diferentes. Portanto, rejeita-se H0 ( $\mathrm{p}=0,00$ que é menor que 0,05$)$. Assim, a idade média de começar a trabalhar na cidade $(15,12)$ é estatisticamente maior do que no campo $(11,79)$. Esta tendência dos residentes rurais começarem a trabalhar mais cedo do que os citadinos foi apontada por vários autores, dentre eles Rambaud (1973), Sen (2000), Teljeur e kelly (2008) e Puia (2011).

Importante destacar a percepção de Chayanov (1974) sobre a dinâmica das unidades agrícolas familiares. Tal autor discute que o princípio básico de organização da unidade econômica familiar agrícola tem como fim a satisfação das suas necessidades. Sendo assim, a dinâmica do trabalho familiar deveria ser concebida simultaneamente como uma unidade de produção e consumo. Neste sentido, as paulatinas transformações verificadas nas unidades produtivas familiares, no âmbito do trabalho, também podem estar associadas à própria cultura rural que valoriza o status de trabalhador em detrimento da escolarização e é voltada para a busca do trabalho rápido, o que tem como consequência a entrada mais precoce no mundo do trabalho. Segundo Rambaud (1973), essa menor predisposição à instrução se deve ao fato de que em uma sociedade com fortes traços rurais se atribuir ao trabalho uma importância primordial. Em suma, todas as variáveis testadas no teste T apresentaram significância menor que 0,05 , ou seja, rejeitaram a hipótese nula. Conclui-se, portanto, que de modo geral, frente as variáveis testadas, as médias entre as populações que vivem no campo e na cidade, em Minas Gerais são diferentes.

Ao se observar a Tabela 2 acima, quanto a principal atividade desenvolvida na exploração agrícola em Minas Gerais, percebe-se que $70,9 \%$ da população que vive no campo desenvolve atividades agrícolas e 29,1\%, atividades não agrícolas. Já em relação à população citadina, 93,5\% desenvolve atividades não agrícolas e 6,5\% exercem atividades agrícolas. Estes dados demonstram que o campo em Minas Gerais apresenta um percentual significativo de atividades não agrícolas, não sendo mais sinônimo de um espaço exclusivamente agrícola, tal como Graziano da Silva (1998, 2000), Favareto e Schroder (2007) e Kageyama (2008) apontaram em relação à realidade paulista.

Quanto ao número de horas trabalhadas por semana, no campo, as pessoas trabalhavam em média 37,02 horas. Quando se observa a cidade nota-se, em primeiro lugar, não haver uma diferença muito significativa da média de horas trabalhadas, já que os indivíduos citadinos trabalham em média 40,02 horas semanais. Em relação ao tipo de trabalho que é desenvolvido pelos habitantes do campo e da cidade, percebe-se que parcela majoritária $(70,8 \%)$ da população que vive no campo desenvolve atividades agrícolas, porém percebe-se também que as atividades não agrícolas, como as atividades domésticas e industriais, representavam juntas 10,6\% das atividades principais desempenhadas no campo.

Já em relação a cidade, percebe-se que 32,6\% das atividades desenvolvidas estavam ligadas ao comércio e a indústria. Porém, nota-se que uma pequena parcela de indivíduos que vivem na cidade (6,5\%) exercem atividades agrícolas. Os dados evidenciam -assim como Nascimento et al (2013, p.8) apontou- que apesar da supremacia da execução de atividades agrícolas pelos moradores do campo e execução de atividades não agrícolas pelos moradores da cidade, o fato de morar no campo ou na cidade não impede o desenvolvimento de atividades agrícolas na cidade e de atividades não agrícolas no campo.

Tabela 2: Perfil socioeconômico dos habitantes do campo e da cidade em Minas Gerais

\begin{tabular}{|l|c|c|}
\hline Variáveis utilizadas no estudo & Campo & Cidade \\
\hline População & $4.236(13,3 \%)$ & $27.601(86,7 \%)$ \\
\hline Sexo & $52 \% \mathrm{H}^{*}$ e $48 \% \mathrm{M}^{* *}$ & $48 \% \mathrm{H}$ e $52 \% \mathrm{M}$ \\
\hline Idade Média & 34,47 anos & 33,53 anos \\
\hline
\end{tabular}




\begin{tabular}{|c|c|c|}
\hline Média de membros por família & 4,01 & 3,84 \\
\hline Casamento Civil e religioso & $67,4 \%$ & $56,6 \%$ \\
\hline Relação conjugal não formal & $19,2 \%$ & $26,5 \%$ \\
\hline Média dos anos de estudo & 5,12 & 7,72 \\
\hline Alfabetizados & $78,3 \%$ & $87,4 \%$ \\
\hline Média do rendimento mensal & $\mathrm{R} \$ 432,61$ & $\mathrm{R} \$ 852,63$ \\
\hline $\begin{array}{l}\text { Média daidade em que começou a } \\
\text { trabalhar }\end{array}$ & 11,79 anos & 15,12 anos \\
\hline Atividades não agrícolas & $29,1 \%$ & $93,5 \%$ \\
\hline Desenvolve apenas 1 trabalho & $96,3 \%$ & $95,9 \%$ \\
\hline Desenvolve 2 ou mais trabalhos & $3,7 \%$ & $4,1 \%$ \\
\hline $\begin{array}{l}\text { Horas trabalhadas na atividade } \\
\text { principal }\end{array}$ & $\begin{array}{l}\text { 37,02 horas } \\
\text { (Agricultura) }\end{array}$ & $\begin{array}{l}\text { 40,2 horas } \\
\text { (Comércio) }\end{array}$ \\
\hline Uso da internet por domicílio & $52,6 \%$ & $82,55 \%$ \\
\hline Uso de celular por pessoa & $70,9 \%$ & $93,8 \%$ \\
\hline Posse de televisão & $94,6 \%$ & $98,5 \%$ \\
\hline Posse de geladeira & $92,2 \%$ & $98,6 \%$ \\
\hline Máquina de lavar & $17,3 \%$ & $54 \%$ \\
\hline Fogão & $98,7 \%$ & $99,6 \%$ \\
\hline $\begin{array}{l}\text { Posse de meios de transporte } \\
\text { (carro ou moto) }\end{array}$ & $59,2 \%$ & $57,4 \%$ \\
\hline Água encanada & $89,8 \%$ & $99,5 \%$ \\
\hline Luz elétrica em casa & $99,2 \%$ & $99,9 \%$ \\
\hline Casa de alvenaria & $98,8 \%$ & $99,6 \%$ \\
\hline
\end{tabular}

*H= homem; **M= mulher. Fonte: Dados do IBGE, 2011.

Ao se observar o número de trabalhos exercidos pelos respondentes na semana de referência, verificou-se que 96,3\% dos rurais e 95,9\% dos citadinos exerciam apenas uma atividade. Enquanto que 3,5\% dos rurais e 3,8\% dos citadinos em Minas Gerais exerciam dois trabalhos. Quanto ao exercício de três atividades ou mais, observou-se apenas em 0,3 \% dos citadinos e em 0,2\% dos rurais. Estes dados revelam que os indivíduos que viviam no campo e na cidade exerciam, em sua esmagadora maioria, apenas uma atividade.

Quanto ao acesso às tecnologias da informação e da comunicação (TICs), em Minas Gerais observou-se que o uso da internet no domicílio, no campo foi de 52,6\%, enquanto que na cidade foi de 82,55\%. Em relação à posse de telefone móvel celular observou-se que 70,9\% dos indivíduos que viviam no campo possuíam celular, enquanto que na cidade essa porcentagem foi de $93,8 \%$. No que se refere à posse de televisão em cores, percebeu-se que 94,6\% dos indivíduos que viviam no campo e 98,5\% daqueles que residiam na cidade tinham acesso a esse bem de consumo. Assim, no que diz respeito às TICs, as diferenças só não foram significativas no que diz respeito à posse de televisão colorida. Para Wanderley (2009), o fornecimento de serviços e realização de uma série de atividades marcadamente urbanas vem dinamizando a sociedade rural confluindo para o hibridismo entre os aspectos da vida rural e da vida citadina.

No que se refere aos bens de consumo, a posse de eletrodomésticos se configurou da seguinte maneira: quanto à geladeira observou-se que a frequência da mesma foi alta tanto no campo como na cidade: 92,2\% e 98,6\%, 
respectivamente. Já quanto à posse de máquina de lavar, 17,3\% dos domicílios no campo a possuíam, enquanto na cidade este percentual aumentou para $54 \%$. No que diz respeito à posse de fogão com mais de duas bocas, $98,7 \%$ dos domicílios no campo e 99,6\% dos domicílios na cidade os possuíam. Quanto à posse de meios de transporte (carro ou moto), observou-se que a porcentagem no campo foi de 59,2\%, enquanto na cidade foi menor (57,4\%). Este dado revela que as pessoas que vivem no campo podem apresentar uma carência nos serviços de transporte público o que os leva a possuírem veículos próprios.

Este crescente uso e aquisição de meios de transporte e bens de consumo vem transformando os modos de morar e viver tipicamente rurais. Neste sentido, os processos de hibridismo cultural permitiriam entender que as transformações do período atual ocorrem em diferentes velocidades e expressam mudanças, permanências e mesclas. As transformações imateriais, aquelas condizentes a mudanças de atitude e de mentalidade podem ser ainda mais lentas do que as transformações materiais. Quanto à posse de água canalizada, percebeu-se que em 89,8\% dos domicílios no campo e 99,5\% dos domicílios citadinos havia acesso à água encanada no estado de Minas Gerais. Em relação à iluminação elétrica do domicílio, ambas as populações apresentaram frequências muito próximas e altas, sendo a mesma de 99,2\% no campo e de 99,9\% na cidade. Quando se observa o tipo de material predominante nas habitações percebeu-se que 98,8\% das habitações do campo eram de alvenaria, acontecendo o mesmo em 99,6\% das habitações citadinas. Nesse sentido, os resultados foram condizentes com os resultados encontrados por Graziano da Silva (1998, 2000), Favareto \& Schroder (2007), e Kageyama (2008), que apontaram como uma das principais características do novo rural a transformação nos modos de vida e modos de morar da população que vive no campo, tornando-se consumidor de bens e serviços urbanos. Enfim, o hibridismo, ou seja, a mescla entre elementos da cultura urbana e da rural, passa a fazer parte dos modos de morar e viver no campo (Canclini, 1998, e Burke, 2010).

\section{Considerações Finais}

Ao fim deste estudo ficou evidente a influência da cultura urbana sobre as sociedades rurais. A pesquisa evidenciou a aproximação parcial entre o perfil sociodemográfico da população urbana e rural em Minas Gerais. O trabalho mostrou que em termos do nível de escolaridade, da renda, do acesso às TICs e a alguns eletrodomésticos como a máquina de lavar roupa, ainda existem diferenças significativas entre as pessoas que vivem no campo e na cidade.

Entretanto, percebeu-se também que o modo de vida urbano vem penetrando de forma clara no campo, principalmente pela via do consumo, como expressam as variáveis referentes aos bens de consumo duráveis e aos meios de transporte, que manifestaram grande proximidade em termos do perfil de citadinos e rurais. Desta forma, uma contribuição social e científica desta investigação foi produzir informações que apontam a necessidade de repensar as políticas públicas direcionadas ao campo, que devem perceber que o campo e a cidade estão cada vez mais integrados, além de compreender que o campo vem se constituindo em uma realidade diversa daquela representação que o antagonizava à cidade quanto as suas características físicas, culturais e aos processos sociais que nele se desenvolvem. É, então, neste contexto de metamorfoses sociais, econômicas e políticas que as discussões sobre as relações entre o campo e a cidade são, na contemporaneidade, de demasiada relevância por dar conta de seus novos conteúdos e novas formas.

\section{Notas}

1 Adota-se nesse trabalho a concepção de campo e cidade como assentamentos humanos e, portanto, formas espaciais e rural e urbano como um conteúdo social, como modos de vida construídos pelos sujeitos sociais. Rambaud, 1969.

$\underline{2}$ Foi um projeto temático denominado Caracterização do Novo Rural Brasileiro, do Núcleo de Economia Agrícola do IE-Unicamp, onde pretendiam analisar as principais transformações ocorridas no meio rural em 11 
unidades da Federação (PI, RN, AL, BA, MG, RJ, SP, PR, SC, RS e DF) reconstruindo séries históricas através de dos dados da Pesquisa Nacional por Amostra de Domicílios (Pnad). Foi apoiado pela FAPESP, pelo programa de Núcleos de Excelência (Pronex/CNPq/Finep) e pela Secretaria de Desenvolvimento Rural do Ministério da Agricultura e do Abastecimento (SDR/MMA).

\section{Referências Bibliográficas}

Abramovay, R. (2009). O futuro das regiões rurais. Porto Alegre: Editora da UFRGS.

Bagú, S. (2003). Tiempo, realidad social y conocimiento. Buenos Aires: Siglo XXI

Bernardelli, M. L. (2010). O caráter urbano das pequenas cidades da região de Catanduva - SP. Em M. E. B Sposito; A. M. Whitacker (Eds.), Cidade e Campo: relações e contradições entre urbano e rural, (pp. 217-247). São Paulo: Expressão Popular.

Biazzo, P. P. (2008). Campo e rural, cidade e urbano: distinções necessárias para uma perspectiva crítica em Geografia Agrária. IV Encontro Nacional de Grupos de Pesquisa - ENGRUP, Anais...São Paulo.

Bibby, P. \& Shepherd, J. (2004). Developing a new classification of urban and rural areas for policy purposes-the methodology. National Statistics, 1-30. Disponível em:

https://www.gov.uk/government/uploads/system/uploads/attachment data/file/239084/2001-rural-urbandefinition-methodology-technical.pdf

Bourdieu, P. (2002). A casa ou o mundo ao contrário. Esboço de uma teoria da prática. Oeiras: Celta.

Burke, P. (2003). Hibridismo Cultural. Rio Grande do Sul: Editora Unisinos.

Camarano, A. A; Abramovay, R. (1998). Êxodo Rural, Envelhecimento e Masculinização no Brasil: panorama dos últimos cinquenta anos. Rev. Bras. Estudos da População, 15(2), 45-65. Disponível em: http://www.abep.nepo.unicamp.br/docs/rev inf/vol15 n2 1998/vol15 n2 1998 4artigo 45 65.pdf

Camargo, R. A. L.; Oliveira, J. T. A. (2012). Agricultura familiar, multifuncionalidade da agricultura e ruralidade: interfaces de uma realidade complexa. Cienc. Rural, 42(9), 1707-1714. Disponível em: http://www.scielo.br/pdf/cr/v42n9/a26712cr3475.pdf

Canclini, N. G. (1998). Culturas Híbridas: Estratégias para entrar e sair da modernidade. $2^{\circ}$ ed. São Paulo: EDUSP.

Carneiro, M. J. (1998). Ruralidade: novas identidades em construção. Estudos Sociedade e Agricultura, 11, $53-75$. Disponível em: http://r1.ufrrj.br/esa/V2/ojs/index.php/esa/article/viewFile/135/131.pdf

Carneiro, M. J. (2006). Pluriatividade da agricultura no Brasil: uma reflexão crítica. Em S. Schneider (org.). A Diversidade na Agricultura Familiar (pp.165-185). Porto Alegre: UFRGS Editora.

Carneiro, M. J. (2012). Ruralidades Contemporâneas: modos de viver e pensar o rural na sociedade brasileira. Rio de Janeiro: Mauad X.

Chayanov, A. V. (1974). La organización de la unidad económica campesina. Buenos Aires: Nueva Visión.

Diniz, F. (1996). Um índice de ruralidade para as nuts do alto trás-os-montes e douro. $5^{\circ}$ Congreso Desarrollo Rural. Anais...Ávila: Disponível em: http://www.jcyl.es/jcyl/cee/dgeae/congresos ecoreg/CERCL/52903.pdf

Endlich, Â. M. (2010). Perspectivas sobre o urbano e o rural. Em M. E. B. Sposito, A.M. Whitacker (org.), Cidade e campo: relações e Contribuições entre urbano e rural (pp. 11-31). São Paulo: Editora Expressão Popular. 
Favareto, A. S.; Schröder, M. (2007). Do território como “ator” ao território como “campo”: uma análise da introdução da abordagem territorial na política de desenvolvimento rural no Brasil. XIV Congresso da Sociedade Brasileira de Economia e Sociologia Rural. Anais...Londrina.

Favareto, A. (2007). Paradigmas do Desenvolvimento Rural em Questão. São Paulo: Iglu: FAPESP.

Hair, J. F; Black, W. C.; Babin, B. J.; Anderson, R. E.; Tatham, R. L. (2009). Análise Multivariada de Dados. $6^{a}$ Edição. Porto Alegre: Ed. Bookman.

Ibge. (2011). Sítio oficial do Instituto Brasileiro de Geografia e Estatística. Disponível em http://www.ibge.gov.br

Kageyama, Â. (2008). Desenvolvimento Rural: conceitos e aplicação ao caso brasileiro. Porto Alegre: Editora da UFRGS.

Lefebvre, H. (2008). A revolução urbana. Belo Horizonte: UFMG.

Nascimento, P. F.; Fiúza, A. L. C.; Pinto, N. M. A. (2013). A nova dinâmica campo-cidade revelada pelo turismo rural: o caso de Venda Nova do Imigrante - ES. Campo-Território: Revista de Geografia Agrária, 8(15), 1-21. Disponível em: http://www.seer.ufu.br/index.php/campoterritorio/article/viewFile/22082/12070.pdf

Nascimento, P. F.; Fiúza, A. L. C.; Ferreira, M. A. M.; Pinto, N. M. A. (2014). O turismo rural e as reconfigurações territoriais em questão: a força da identidade cultural para o desenvolvimento nas montanhas capixabas. Organizações Rurais \& Agroindustriais, 16(2), 178-191. Disponível em: http://www.spell.org.br/documentos/ver/32108/o-turismo-rural-e-as-reconfiguracoes-territoriais-em-questao--aforca-da-identidade-cultural-para-o-desenvolvimento-nas-montanhas-capixabas.pdf

Olatunde, S.; Leduc, E. \& Berkowitz, J. (2007). Different practice patterns of rural and urban general practitioners are predicted by the General Practice Rurality Index. Can J Rural Med, 12(2), 73-80.

Pereira, E.; Pereirinha, J.; Passos, J. (2009). Desenvolvimento de índices de caracterização do território para o estudo da pobreza rural em Portugal Continental. Revista Portuguesa de Estudos Regionais, 6, 14-28.

Puia, O. A. (2011). The Evaluation of Rural Space through the Analysis of the Rurality Index. Case Study: the Villages of Sălaj East of Jibou. Forum geografic, 10(2), 264-275.

Rambaud, P. (1969). Société Rurale et Urbanisation. $1^{a}$ ed. Paris: Ed. du Seuil.

Rambaud, P. (1973). Société rurale et urbanisation. $2^{a}$ ed. Paris: Éditions du Seuil.

Remoaldo, P. C. (2002) Desigualdades territoriais e sociais subjacentes à mortalidade infantil em Portugal. Série Textos Universitários de Ciências Sociais e Humanas. Lisboa: Fundação Calouste Gulbenkian, Ministério da Ciência e da Tecnologia.

Sánchez, H. (2009). Periurbanización y espacios rurales en la periferia de las ciudades. Procuraduría Agraria, Estudios Agrarios. 41,93-123.

Santos, M. (1993). A Urbanização Brasileira. São Paulo: Hucitec.

Silveira, M. L. (2003). O Brasil: território e sociedade no início do século XXI. Rio de Janeiro: Record.

Sen, A. K. (2000). Desenvolvimento como liberdade. [s.l.] São Paulo: Companhia das Letras

Silva, J. G. da; Del Grossi, M. E. (1998). A evolução do emprego rural não-agrícola no meio rural brasileiro. Seminário Internacional Campo-Cidade. Anais...Curitiba.

Silva, J. G; Del Grossi, M. E. (2000). O novo rural brasileiro. Debates Socio Ambientais, 6(14),16-18.

Silva, M. C. (2013). Sócio-antropologia rural e urbana. Fragmentos da sociedade portuguesa (1960-2010). Porto: Edições afrontamento. 
Sobarzo, O. (2006). O rural e o urbano em Henri Lefebvre. Em M. E. B. Spósito; A. M. Whitacker, Cidade e Campo: Relações e Contradições entre urbano e rural (pp. 53-64). São Paulo: Expressão Popular.

Sorokin, P.; Zimmerman, C. C.; Galpin, C. (1981). Diferenças fundamentais entre o mundo rural e o urbano. Em J. S. Martins, Introdução crítica à sociologia rural (pp. 198-224). São Paulo: Editora Hucitec.

Souza, R. P.; Souza, M. S. (2008). O debate brasileiro sobre pluriatividade: implicações sobre o desenvolvimento rural e as políticas públicas. XLVI Congresso da Sociedade Brasileira de Economia, Administração e Sociologia Rural. Anais...Rio Branco.

Teixeira, M. A; Lages, V. N. (1997). Transformações no espaço rural e a geografia rural: idéias para discussão. Revista de Geografia, 14, 9-33.

Teljeur, C. \& Kelly, A. (2008). An urban-rural classification for health services research in Ireland. Irish Geography, 41(3), 295-311. Disponível em: http://irishgeography.ie/index.php/irishgeography/article/viewFile/124/116

United Nations. (2012) World urbanization prospects: the 2011 revision. [s.l.] UN.

Veiga, J. E. (2002). Cidades imaginárias: o Brasil é menos urbano do que se calcula. Campinas: Autores Associados.

Waldorf, B. (2007). What is rural and what is urban in Indiana? Research Paper. Purdue Center for Regional Development Report, PCRD-R-4, 1-20.

Wanderley, M. N. B. (2009). O mundo rural como espaço de vida - reflexos sobre a propriedade da terra, agricultura familiar e ruralidade. Porto Alegre: UFRGS Editora.

Weinert, C. \& Boik, R. J. (1995). Msu. Rurality Index: development and evaluation. Montana State University. Research in nursing health, 18, 453-464. 